\title{
Use of Different Trading Environments Around Interim Earnings Announcements on the Helsinki Stock Exchange
}

\author{
Markku Vieru \\ University of Oulu, Finland
}

This paper tests the hypothesis that an anticipated information event affects the use of trading venues. Data from the Helsinki Stock Exchange are used where an upstairs market co-exists with a downstairs market. Trades are classified also as in-house trades and externalized trades. This paper suggests that interim earnings announcement affects where trades are executed. The results indicate that an anticipated announcement increases downstairs trading before the announcement event. Correspondingly trades in the upstairs market tend to decrease before the announcement. After the announcement upstairs trading recovers. Furthermore, the empirical findings suggest that the in-house trades in the upstairs market are positively related to the liquidity and volatility during the pre-announcement period. After the announcement the volatility association changes resulting in increased downstairs trading with high volatility. The results suggest that after the announcement trades are more information-motivated and high volatility is associated with a larger proportion of downstairs trading (JEL D23, D82, G18).

Keywords: event study, information asymmetry, accounting disclosure, thin securities markets, trading behavior.

\section{Introduction}

Financial markets usually provide a variety of trading venues, reflecting investors' heterogeneity. Glosten (1994) investigates the efficiencies related to consolidated trading in an electronic limit order book, which

\footnotetext{
*The author thanks Tapani Kovalainen, Jukka Perttunen, Markku Rahiala, Hannu Schadewitz, two anonymous referees and the seminar participants at the 2001 European Accounting Association meetings and 2002 European Finance Association meetings for helpful comments and suggestions on the earlier draft of the paper.
}

(Multinational Finance Journal, 2003, vol. 7, no. 3 \& 4, pp. 131-152)

(C) Multinational Finance Society, a nonprofit corporation. All rights reserved. DOI: $10.17578 / 7-3 / 4-2$ 
is similar to downstairs market term (used in this paper) where trades are anonymously executed. Nevertheless, virtually every stock market is accompanied by a parallel upstairs market. The upstairs market refers to the market where a broker seeks counter-parties with whom to trade. According to Harris (2002), markets become fragmented when the benefits from trading differentiation exceed the benefits from consolidation. The existence of such distinct trading systems raises questions about the use of these markets in different trading conditions; that is, how the release of information affects the use of trading venues.

The existence of upstairs and downstairs markets has spurred a lot of research. In particular, the issues of order exposure and information content of a trade have received great attention in the literature. Seppi (1990) suggests that an uninformed trader may trade in the upstairs market where innocent trading motives can be presented. As a consequence, traders with the ability to choose their trading environments may benefit from the coexistence of these markets; e.g., Grossman (1992) and Cheng and Madhavan (1997). Thus, large traders who execute deals solely for liquidity reasons rather than informational motives have incentives to be identified. As a matter of fact, the trades in the upstairs market are found to contain less information and have a smaller permanent price effect than trades in the downstairs market; see Keim and Madhavan (1996), and Booth et al. (2002).

Evidence is found that the volatility and liquidity can affect the use of different trading environments. Seppi (1990) suggests that the use of the upstairs market may be associated with liquidity. Madhavan and Cheng (1997) and Smith, Turnbull and White (2001) suggest that trades of more volatile stocks and illiquid stocks are likely to executed in the downstairs market, as it is expected that such stocks have greater information asymmetry and that trades are more information-motivated. Kim and Verrecchia (1991) propose that information asymmetry is greater prior than after to earnings announcements. ${ }^{1}$ Prior research suggests that anticipation and the use of private information systems encourages some traders to carefully judge whether they should execute a trade in the upstairs market rather that in the downstairs market.

In spite of active research on the use of trading venues little attention has been paid as to how traders consider and use different trading venues around the informational events. In this paper the use of

1. Consistent with Kim and Verrecchia (1991), Vieru (2002) finds that earnings announcement decreases the permanent price effects of larger trades in Finland. 
different trading venues around interim report announcements is examined using data from the Helsinki Stock Exchange (HSE) in Finland. The data from this particular exchange is used because the HSE not only identifies the brokerage houses on both sides of a transaction but also indicates when the trade was made, and whether it was executed in the downstairs or the upstairs market. In order to get more release events, interim earnings announcements are chosen rather than annual earnings announcements.

This paper extends the current research in three main respects. First, prior theoretical and empirical research suggests that trading around earnings announcement is affected by pre-disclosure information asymmetry, the information content of the announcement, differential interpretations of the announcement, production of new private information and firm size; see Kim and Verrecchia (1991), (1994) and (1997), Kandel and Pearson (1995) Bamber et al. (1997), (1999) and (2002) and in Finland, Vieru (1998). In this paper, new evidence shows that the relative use of alternative trading environments is also affected by anticipated information events.

Second, the HSE data allows us to study whether the release of information affects internalization. Internalization represents a situation where a broker executes an order in-house (Huang and Stoll 1996). While Smith, Turnbull and White (2001) study whether upstairs brokers can screen out information-motivated orders, this study indicates that the proportion of internalization is lower before an announcement event than after the announcement. This is consistent with Seppi (1990), who suggests that upstairs trading is based on innocent trading motives which may be hard to express before the announcement.

Third, Smith et al. (2001) and Hedvall (1996) among others focus on factors related to the use of the upstairs market. Nevertheless, with comprehensive data it is possible to distinguish same- and cross-broker trades from each other. Booth et al. (2002) suggest that externalization in the upstairs market exposes the broker to front running and affects the distribution of trading costs. ${ }^{2}$ The findings show that the internalization is positively related to the liquidity and volatility during the pre-announcement period. After the announcement the association changes, resulting in increased downstairs trading with high volatility.

2. Booth et al. (2000) find that price clustering is more evident for internalized traders than other trades. Booth et al. (2001) hypothesized that liquidity increases the propensity for internalization. 
The rest of the paper is organized as follows: section II discusses the trading system of the HSE and collection of data. Section III discusses the testing procedures. Section IV presents the empirical results. The paper ends with a summary and concluding remarks.

\section{HSE Trading and Data}

\section{A. Trading system and descriptive statistics}

The Helsinki Stock Exchange (HSE) is the only stock exchange operating in Finland. The HSE's trading system, called the HETI, is a distributed, fully-automated order-driven system. It is a strict market-by-order type mechanism with no affirmative requirements to make a market or provide price continuity (as are the NYSE specialists). HSE's open limit order book resembles the continuous automated trading system (CATS) used on several large exchanges. However, it differs with respect to the non-existence of market orders except for odd lot matching. Consequently, it prevents sweeping of the book with a single order. The identity of the broker behind each limit order is displayed to the member of the exchange.

Trading on the HSE begins with an opening call (pre-trading). During continuous trading, downstairs market brokers continue to enter order-based buys and sells that are automatically matched into deals. Along with the continuous limit order book-trading, prearranged trades (upstairs market) can be carried out inside the current bid-ask spread.

In the upstairs market, the counter party is known precisely by the broker, even though the clients may remain unknown to each other. One broker acts as an agent for both the buyer and the seller, or effectively as a market maker. Knowledge of the motives of traders may allow brokers to arrange large-block trades without adverse price changes for the initiator.

When a broker successfully finds counter-parties for a trade, the trade is executed as an internalized trade where the buying broker and the selling broker is the same. ${ }^{3}$ Odd lots trades are matched frequently

3. According to the HSE's procedures, unless specifically directed by the initiator of the trade, the choice of the trading venue is the broker's. The trade has to be reported in the HETI system within five minutes. Because orders filled in the upstairs market are reported in the HETI system, the public can tell when a trade is executed upstairs. If the trade did not change any outstanding limit orders, the trade was executed upstairs. Brokers on the HSE are free to participate either in the upstairs market or in the downstairs market or in both. 
at the latest prices for a lot trade. After-hours trading (After-market trading I and II) has to be carried out inside the maximum price range bounded by the closing spread and the high/low transaction prices during the trading day. A more detailed description of the HSE's trading system can be found in Hedvall (1996).

The database used in this study is exceedingly comprehensive, consisting of all of the HSE's stock transactions from January 1, 1993 to December 31, 1997. The data available from the HSE includes the date, time, price, trade size, trading mode (after-hours trading, prearranged trading, round lot trading, pre-trading, or odd lot trading) and code of the selling and buying broker/dealer involved in each trade executed. The database contains 1,694,563 individual trades in this period, meaning an average of 1,356 trades per day. ${ }^{4}$ Despite the recent rapid development of the Finnish stock market, it was still rather small and illiquid during the research period. ${ }^{5}$ During the research period trades were executed by 30 different brokers/dealers.

Table 1 gives the first insight into how trading venues affect trade size. Trades executed outside the limit order book (upstairs market and after-hours trading) are especially large in size. For example, the mean round lot trade size in the downstairs market is FIM (Finnish markka) 178,476 ( 1 EUR $=6$ FIM), whereas in the upstairs market the mean size is FIM 643,472 and in after-hours trading the mean is FIM 645,327. Table 1 suggests that the downstairs market comprises more than half of the whole market. For comparison, Smith, Turnbull, and White (2001) indicate that over 50\% of the total order flow is carried out in the upstairs market on the Toronto Stock Exchange.

\section{B. Sample}

HSE's rules require firms to announce to the public the date(s) on which

4. "New" shares were excluded. Compared to "old" shares they do not provide a full dividend per share and they were traded only for a short period of time.

5. For example, at the end of 1997, 126 firms were listed on the HSE, with a market capitalization of FIM 402 billion. Year-end share turnover relative to market capitalization in 1997 was $47.0 \%$. A special feature of the list due to the success of Nokia Corporation is the heavy concentration of trading in that stock. Nokia alone accounts for $41.8 \%$ of share turnover and $29.9 \%$ of total market capitalization in 1997. Consequently, the high-tech industry plays a dominant role in the HSE. To illustrate, the telecommunication and electronic industries represent $31.1 \%$ and $42.3 \%$ of the year-end market value and annual turnover of HSE in 1997, respectively. Corresponding figures for the forest industry are $12.9 \%$ and $14.6 \%$, respectively. 


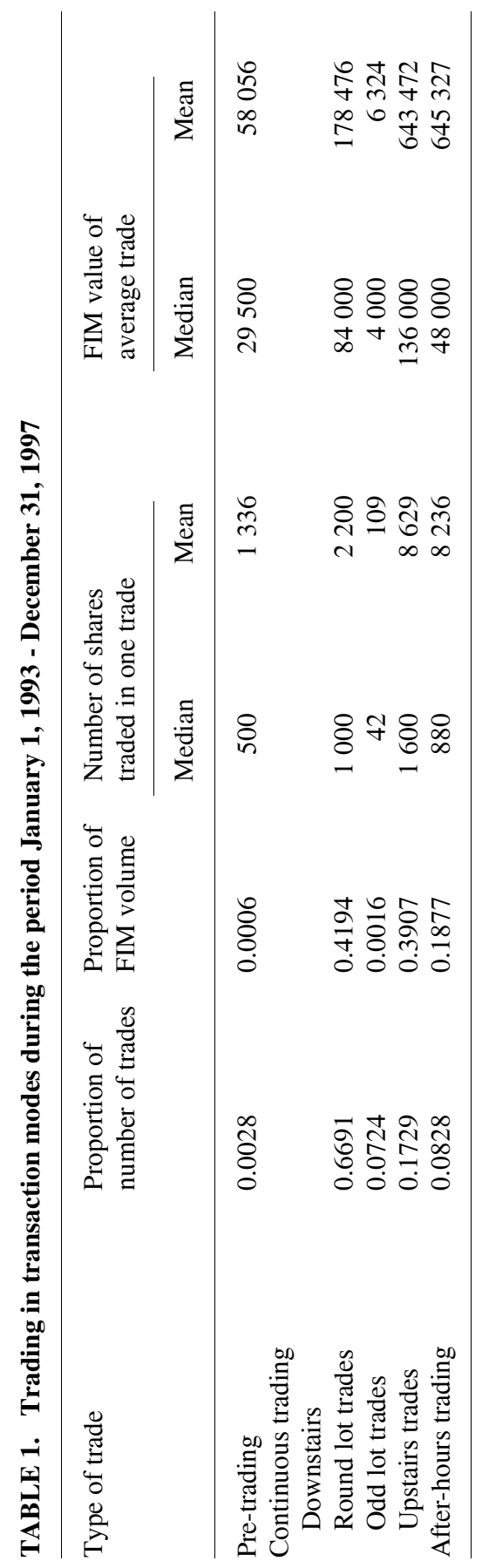


their interim report(s) will be released. The interim earnings disclosure dates of the firms are provided by the HSE. During the sample period (1993-97) there were 432 interim earnings announcements released by the HSE's firms that were accepted in the sample. ${ }^{6}$ Several firms have multiple issues (different classes of shares) listed on the HSE. These issues typically differ in their voting power and/or dividend entitlement. This makes the issues imperfect substitutes for each other and may result in different owner clienteles. Therefore, the share classes of the underlying firm are considered to be separate stocks. This results in a total of 767 interim earning announcement events.

Non-trading days are common for many stocks listed on the HSE, and if all stock issues are used, it would result in a lot of zero observations. Therefore, an announcement is accepted into the sample if the corresponding stock has at least one trade observation on each day during the time period -5 to +5 relative to the announcement day 0 . This resulted in a total of 405 interim earnings announcement events. The content of the interim reports during the research period was stipulated by the rules by the HSE concerning interim reports and by the Securities Markets Act. The current legislation and regulation of interim reports in Finland conform to EU practices.

Typically the calendar year and the fiscal year of a firm are the same, resulting in clustered interim earnings releases. Information is probably transferred from one firm to another firm, especially within the same industry, which may cause cross-sectional trading dependencies. However, the firms in the sample represent a wide variety of industries, which reduces the problems associated with announcement-time clustering. The frequency of reporting has increased. During 1993, our first sample year, about $60 \%$ of the HSE-listed firms published at least two interim reports. The corresponding figure for 1997 was about $80 \%$.

According to the Securities Markets Act, the rules related to insider trading have changed during the research period. Before July 26, 1996 short-term trading by insiders was prohibited. Short-term trading was defined as six months. An amendment to the Securities Markets Act abolished the 6-month trading rule and the public insider register was introduced. According to the Act an individual who is considered to be

6. Only companies listed on the HSE's official list (71 at the end of 1996) was selected in the sample. The firms listed on the OTC list and on the Brokers' list were relatively illiquid and small in size, so they were omitted. Those announcements which were omitted tended to be releases of summaries of performance rather than interim reports as such. Releases by newly listed firms (IPO-firms) were also omitted. 
an insider is obliged to announce to the public all changes in stockholdings. In addition, the HSE has issued rules on trading of insiders in listed companies that restrict pre-announcement trading. On the announcement day the crucial question is the time when the announcement is due to be released. ${ }^{7}$

\section{Hypotheses and Methodology}

Based on prior studies, it is hypothesized that an anticipated earnings announcement affects the use of different trading environments. In particular, before the announcement the proportion of upstairs trading is assumed to decrease. Kim and Verrecchia (1991) suggest that anticipated information releases encourage investors to acquire private information prior to the firm's announcement. This may increase traders' needs to trade anonymously.

On the other hand, Seppi (1990) proposes that upstairs trading is based on innocent trading motives. Also brokers may protect the interests of their customers by not exposing their customers' unexpressed demand during a period of large information asymmetry (Grossman 1992). As suggested by Smith, Turnbull and White (2001) upstairs brokers can effectively screen out information-motivated orders. Consequently information-oriented trades will increase and liquidity motivated trades will decrease before the announcement. Thus, an anticipated announcement may increase trading costs in upstairs markets relative to costs in downstairs markets (Bessembinder and Venkataraman 2004).

The use of trading venues is hypothesized to depend on liquidity and volatility. It is expected that liquidity facilitates upstairs markets, given the lower order execution costs suggested in Seppi (1990) and Madhavan and Cheng (1997). Trades of more volatile stocks and illiquid stocks are expected to be sent to the downstairs market, as it is

7. Earnings announcements are released throughout the day. Some firms announce even before the market open or near the market close. A more finely defined announcement time would contribute to the analysis. Since the sample period is relatively long, an exact announcement time was not available throughout the sample period. Thus, for example, if an announcement is released early in the trading day, a change in the use of the trading venues may occur already on the announcement day. Correspondingly, a late release may shift the change in the use of the trading venues to the subsequent trading day. Thus timing differences may decrease the likelihood of finding differences in the use of trading venues around the announcement. 
expected that such stocks have greater information asymmetry and that trades are more information-motivated as suggested by Madhavan and Cheng (1997) and Smith, Turnbull and White (2001). For liquid stocks there is more pre-disclosure information and higher analysts' coverage so there is less need to change trading venue for these stocks. ${ }^{8}$ Correspondingly, illiquid stocks associated with high volatility are assumed to be associated with lower upstairs trading before the announcement.

Trades are classified also as internalized and externalized trades. As pointed out by Godek (1996) trades may be internalized because of established business relationships. Booth et al. (2002) suggest that brokers may internalize trades in order to hedge for front running or in order to benefit from the bid -ask spread. They find that about $95 \%$ of the upstairs trades are internalized and about $95 \%$ of the downstairs trades are externalized. Internalization in the downstairs market usually occurs randomly because of the anonymous feature of the downstairs market. Thus the basic nature of the trading venues means that same-broker traders are executed in the upstairs market and cross-broker trades are executed in the downstairs market.

\section{A. Tests for Announcement Events}

To study whether an announcement event affects the use of a trading environment, several proxies have to be specified. Data provided by the HSE indicates which trading environment (or trading mode) was used for each single trade. First, the trading mode pattern around the announcement is specified. Second, the 'normal' trading mode pattern prevailing during non-event periods is specified. The shift in the trading mode pattern is denoted by the difference between these two patterns.

More specifically, $P T A_{M, i}^{T}$ is the proportion of trading activity in period $T$ in trading mode $M$ for announcement $i(M=1$ if the trade is a same-broker downstairs trade, $M=2$ if the trade is a cross-broker downstairs trade, $M=3$ if the trade is a same-broker upstairs trade, $M$ $=4$ if the trade is a cross-broker upstairs trade, $M=5$ if the trade is a same-broker after-hours trade, $M=6$ if the trade is a cross-broker after-hours trade). The firm-specific measure takes the following form ${ }^{9}$

8. An anonymous referee is thanked for pointing out this fact.

9. To approximate normality, also log transformations were used. The results were much the same. 


$$
\operatorname{PTA}_{M, i}^{T}=\sum_{t=t_{0}}^{t_{1}} V O L_{M, t, i} / \sum_{t=t_{0}}^{t_{1}} V O L_{t, i}
$$

where $V O L_{M, t, i}$ refers to activity (trading volume in FIM and number of transactions) on day t relative to the announcement date using mode $M$ for announcement $i$.

In order to provide deeper insight into the trading pattern, the length of the pre- and post-announcement periods $T$ was varied. Two pre-announcement periods were specified. The longer period covers the five-day trading period preceding the announcement date $\left[t_{0}=-5, t_{1}=\right.$ $-1]$. The shorter period covers the three-day trading period preceding the announcement date $\left[t_{0}=-3, t_{1}=-1\right]$. Two corresponding periods are specified for the post-announcement period $\left[t_{0}=1, t_{1}=3\right]$ and $\left[t_{0}=1\right.$, $\left.t_{1}=5\right]$. The announcement date is referred to as $t_{0}=t_{1}=0$. The corresponding relative stock trading mode pattern during the non-announcement period, $P T A_{M, \mathrm{i}}^{N}$, is

$$
P T A_{M, i}^{N}=\sum_{t=-30}^{-6} V O L_{M, t, i} / \sum_{t=-30}^{-6} V O L_{t, i}
$$

The normal trading mode pattern covers the 25-day trading period preceding the announcement date $\left[t_{0}=-30, t_{1}=-6\right]$. . Hence, the firm-specific change in trading mode pattern associated with announcement $i$ during period $T$ and mode $M, A C T D I F F_{M, \mathrm{i}}^{T}$ is specified as follows:

$$
A C T D I F F_{M, i}^{T}=P T A_{M, i}^{T}-P T A_{M, i}^{N}
$$

The change in the use of the trading environment was tested using a dummy regression model. The model's basic form is as follows:

$$
A_{C T D I F F}^{T}{ }_{M, i}=a_{1} D_{1, i}^{T}+a_{2} D_{2, i}^{T}+\cdots+a_{6} D_{6, i}^{T}+\varepsilon_{M, i}^{T}
$$

where $D_{1, i}^{T}=1$ for a same-broker downstairs trade $(M=1)$ during period $T$ and 0 otherwise, $D_{2, i}^{T}=1$ for a cross-broker downstairs trade $(M=2)$ during period $T$ and 0 otherwise, $D_{3, i}^{T}=1$ for a same-broker upstairs trade $(M=3)$ during period $T$ and 0 otherwise, $D_{4, i}^{T}=1$ for a cross-broker 
upstairs trade $(M=4)$ during period $T$ and 0 otherwise, $D_{5, i}^{T}=1$ for a same-broker after-hours trade $(M=5)$ during period $T$ and 0 otherwise, and $D_{6, i}^{T}=1$ for a cross-broker after-hours trade $(M=6)$ during period $T$ and 0 otherwise, $a_{1}, a_{2}, \ldots, a_{6}$ are the respective parameters for the six binary (dummy) variables and $\varepsilon_{M, i}^{T}$ is the regression error term.

In order to avoid the dummy variable trap, the model is estimated without an intercept. The estimated parameters can be interpreted as the average deviation of the trading activity pattern in a given mode around the earnings announcement from a corresponding trading mode pattern during a non-announcement period. It is hypothesized that before the announcement the proportion of cross-broker downstairs trading increases resulting in positive values for the estimated parameter $a_{2}$ and negative values for the estimated parameter $a_{3}$ (proportion of in-house upstairs trading). After the earnings announcement, internalized upstairs trading is hypothesized to recover, resulting in positive values for the estimated parameter $a_{3}$ and negative values for the estimated parameter $a_{2}$. The economic importance of other trading venues is lower and explicit hypotheses are not provided.

\section{B. Tests for Different Markets}

The liquidity of an underlying stock issue around interim earnings announcement $i, A C T_{i, t}$, is measured by the logarithmic FIM trading volume and logarithmic number of transactions of a stock on day $t$. Another proxy for the liquidity at a particular point in time is the bid-ask spread. ${ }^{10}$ Bid-ask spreads are computed from closing ask prices and closing bid prices. The relative spread takes the following form:

$$
\operatorname{SPREAD}_{i, t}=\frac{a s k_{i, t}-\operatorname{bid}_{i, t}}{\left(a s k_{i, t}+b i d_{i, t}\right) / 2}
$$

Volatility is measured similarly to Garman and Klass (1980). The Garman-Klass volatility estimator for an underlying stock issue,

10. Spread is frequently understood as an important component of the transaction costs. Being sensitive to changes in adverse selection risk, the market maker uses the spread to manage this risk. There are contrasting views on how the spread behaves around earnings announcements with market makers (see e.g. Lee, Mucklow and Ready 1993; Acker, Stakler and Tonks (2002). In the HSE, there are no designated market makers. It is conceivable that the bid-ask spread may contain information concerning transaction costs not visible in the trading volume. 
$\operatorname{VOLA}_{i, t}$ on day $t$ for announcement $i$, is calculated as follows:

$$
V O L A_{i, t}=0.5\left(\ln P_{i, t}^{\text {high }}-\ln P_{i, t}^{\text {low }}\right)^{2}-(2 \ln 2-1)\left(\ln P_{i, t}^{\text {close }}-\ln P_{i, t}^{\text {open }}\right)^{2}
$$

where $P_{i, t}^{\text {high }}, P_{i, t}^{\text {low }}, P_{i, t}^{\text {close }}$ and $P_{i, t}^{\text {open }}$ are respectively the highest, lowest, closing and opening prices of a stock on day $t$. This volatility estimator provides a more efficient measure for intra-day volatility than daily returns volatility.

The two most important trading venues are selected for further analysis. About half of the FIM volume is generated on a cross-broker basis in the downstairs market and one third on an in-house basis in the upstairs market. Using variables set forth above, the following two basic models are formulated:

$$
\begin{gathered}
C R L O B_{i, t}=b_{0}+b_{1} D+b_{2} A_{C} T_{i, t}+b_{3} \operatorname{VOLA}_{i, t}+b_{4} \operatorname{SPREAD}_{i, t} \\
+b_{5} \mathrm{DACT}_{i, t}+b_{6} \text { DVOLA }_{i, t}+b_{7} \text { DSPREAD }_{i, t} \\
+b_{8} D_{94-95, i, t}+b_{9} D_{96-97, i, t}+e_{i, t}
\end{gathered}
$$

and

$$
\begin{gathered}
\operatorname{INPUT}_{i, t}=c_{0}+c_{1} D+c_{2} A C T_{i, t}+c_{3} \text { VOLA }_{i, t}+c_{4} \text { SPREAD }_{i, t} \\
+c_{5} D A C T_{i, t}+c_{6} \text { DVOLA }_{i, t}+c_{7} D \text { SPREAD } \\
i, t \\
+c_{8} D_{94-95, i, t}+c_{9} D_{96-97, i, t}+u_{i, t},
\end{gathered}
$$

where the subscripts $i$ is for the announcement and $t$ is for the day, $C R L O B$ is the proportion of cross-broker trading in the downstairs market, INPUT is the proportion of in-house trades in the upstairs market, $D$ is a dummy variable taking the value of one for the postannouncement period and the value of zero otherwise, ACT is the natural log of total trading activity, $V O L$ is the Garman-Klass intra-day volatility, SPREAD is the bid-ask spread, $D_{94-95}\left(D_{96-97}\right)$ is a dummy variable taking the value of one for an announcement released during the period November 1, 1994 to December 31, 1995 (January 1, 1996 to December 31,1997$)$ and the value of zero otherwise, $e_{i, t}$ and $u_{i, t}$ are the regression error terms. 
The dummy regression variables D ACT, D VOLA, and D SPREAD capture whether the regression coefficients differ between the pre- and post-announcement periods. The dummy regression terms for $D_{94-95}$ and $D_{96-97}$ capture whether the lengthening of the free trading period set has affected the use of trading environments. ${ }^{11}$

The first model (i.e., equation 7) associates the relative use of cross-broker trading in the downstairs market and transaction costs, intra-day volatility, and bid-ask spread. The second model (i.e., equation 8) associates the relative use of in-house trading in the upstairs market to the same explanatory variables. The models incorporate dummy variables allowing for differential associations with the announcement event. Also binary dummy variables are included to mitigate possible cross-correlation caused by lengthening of the downstairs trading opportunity.

\section{Empirical Results}

\section{A. Trading Environments}

Table 2 reports the change in the use of different trading environments around the interim earnings announcement relative to the non-announcement period based on the FIM trading volume and the number of transactions. The first and second rows of panel A report the change in the use of underlying trading environments during a 5-day and 3-day periods preceding the announcement day. The remaining rows refer to announcement day and the periods after the interim earnings announcement day.

Downstairs trading consists of round lot trades, odd lot trades and trades during the opening call. Non-trading days are common for many stocks listed on the HSE. This means there are differences in variability between actively and thinly traded stocks, causing a heteroskedasticity problem for the regressions. Therefore, the statistical significance was tested by a t-statistic adjusted for an unknown type of heteroskedasticity using White's (1980) estimate of parameter standard error.

Table 2 shows relatively similar results for both FIM trading volume

11. Trading hours during the trading day on the HSE have been changed a couple of times. The free trading period has been lengthened. The changes have been motivated by shifting free trading hours to coincide more closely with the trading in the European and US markets. 


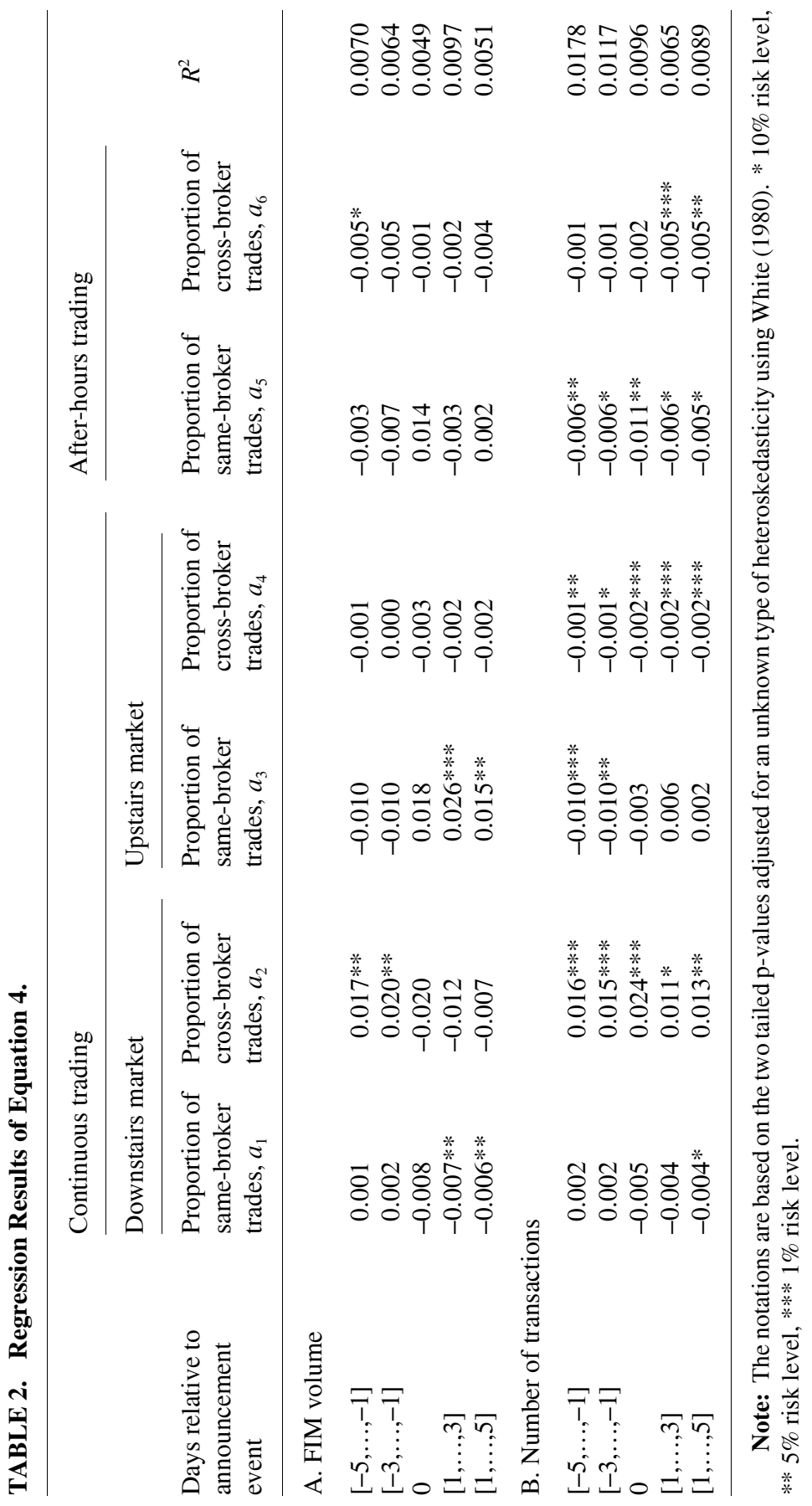


and the number of transactions. Before the announcement trading seems to shift to the downstairs market compared to that during the non-announcement period, whereas relative use of the upstairs market seems to decrease. After the announcement event, in-house upstairs trading seems to recover resulting in predominantly non-negative parameter estimates. The use of after-hours trading seems to be predominantly unaffected by the announcement resulting in insignificant estimates for both the pre- and post-announcement periods.

Theoretical considerations suggest that anticipated information releases encourage investors to acquire private information prior to the firm's announcement (Kim and Verrecchia [1991]). This may increase traders' needs to trade anonymously. This is consistent with Seppi (1990), who suggests upstairs trading is based on innocent trading motives which may be hard to express before the announcement. Also Smith, Turnbull and White (2001) suggest that upstairs brokers can effectively screen out information-motivated orders. Brokers may protect the interests of their customers by not exposing their customers' unexpressed demand during a period of large information asymmetry (Grossman 1992). The evidence seems to be in line with these considerations suggesting that an anticipated announcement increases trading costs in the upstairs market relative to costs in the downstairs market. After the announcement trading costs in the upstairs market seem to be lower.

Supplementary tests using simple time series dummy regression models were performed. ${ }^{12}$ The models test whether the relative use of trading venue has changed after the announcement day $(t=0)$ from its pre-announcement level. The results confirm the previous findings. When FIM trading volumes are used, a statistically significant change is found for the proportion of same-broker trades in the downstairs market $(p=0.027)$, the proportion of cross-broker trades in the downstairs

12. Additional tests that examine whether the results are robust in terms of allowing multiple issues (i.e. different classes of shares) in the underlying firm are also carried out in the analysis. Only the most traded stock of the firm is allowed in the sample. This decreased the number of announcements in the sample from 405 to 334 . Despite the loss of observations, the inferences hold for both samples (results are available on request). Dummy regression models for each of the six trading venues are performed. The models test whether the proportion of use of the trading venue has changed after the announcement day 0 from its pre-announcement level. Regressions take the following form: $A C T D I F F_{t}=a+\beta D_{t}+\mathcal{E}_{t}$, where $a$ represents the pre-announcement level of trading, and $\beta$ the corresponding change of this proportion after the announcement, $D=1$, if $t=(0,1, \ldots, 5)$, otherwise $t=(-5,-4, \ldots,-1)$ $D=0$, and $\varepsilon_{t}$ is the error term. 
market $(p=0.003)$, and the proportion of same-broker trades in the upstairs market $(p=0.002)$. When the number of transactions is used, a statistically significant change is found for the proportion of same-broker trades in the downstairs market $(p=0.032)$, and the proportion of same-broker trades in the upstairs market $(p=0.008)$.

\section{B. Trading Environment}

In this section we assess whether the association between the relative use of cross-broker trading in the downstairs market and in-house trading in the upstairs market is changed with liquidity and volatility in the HSE around the announcement.

Table 3 reports the OLS estimation results for the models. Turning first to model 1 , it seems that liquidity, volatility and dummy variables provide a significant explanation $(F$-test $p<0.01)$ for cross-broker trading in the downstairs market. The relative use of cross-broker trading in the downstairs market is significantly negatively associated with the FIM trading volume, $A C T$, volatility, VOLA, and bid-ask spread, SPREAD. The findings are quite similar regardless of whether the liquidity measure is based on FIM volume or the number of transactions. However, the results based on the number of transactions as a liquidity measure suggests a significantly positive relationship. This difference means that large trades associated with infrequent trading are more likely to be executed in the upstairs market.

The dummy variables representing the post-announcement relation indicate a changed pattern compared to the pre-announcement period. For example, after the announcement the high volatility is no longer channeling trades to the upstairs market. This is probably related to the traders' willingness to benefit from the announcement. Consequently, after the announcements trades are more information-motivated. Thus, volatility seems to be translated differently for traders before and after the announcement. Before the announcement, the more volatility, the more imminent is the problem of limit orders being won by better informed investors proxying execution risk in the downstairs market. When the information is released, traders try to take advantage of public information using the downstairs market.

Finally, the results suggest that the relative use of an internalized trading venue (model 2$)$ is positively $(p<0.01)$ associated with the liquidity (both FIM trading volume and number of transactions). Also a wider bid-ask spread is associated with internalizing. This suggests that 


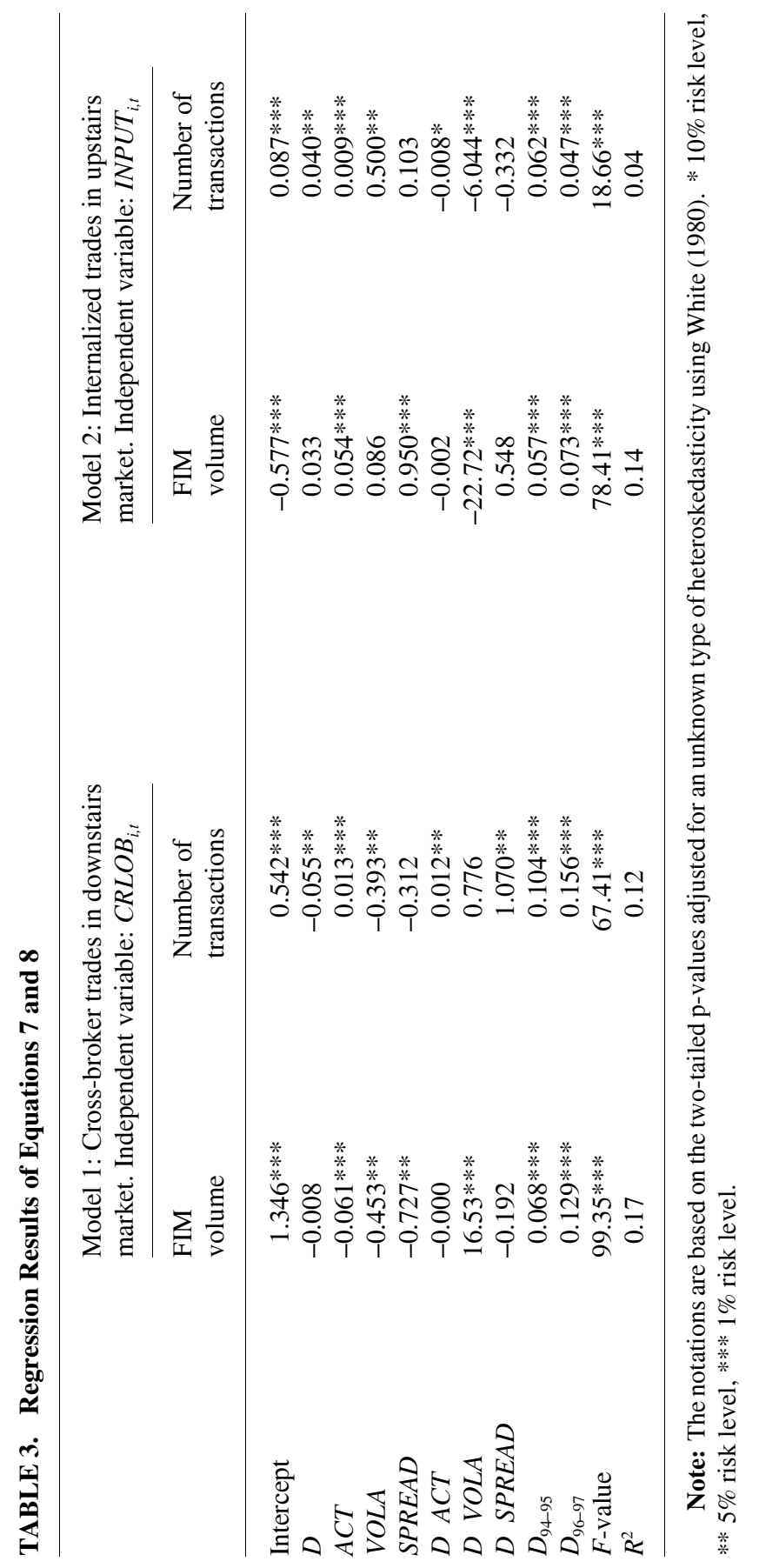


the trading is channeled to the in-house upstairs trading venue if the stock is characterized as being liquid. This is in line with Seppi (1990) and Cheng and Madhavan (1997), who suggest that high liquidity and a narrow bid-ask spread supports upstairs markets. Also volatility seems to be positively related to the proportion of in-house trading before the announcement. The statistical significance depends on whether FIM volume or number of transactions is used as a trading activity measure. A statistically significantly positive relation between and the bid-ask spread suggests that the wider spread provides more room for price negotiation in the upstairs market, which facilitates upstairs trading. Consistent with Seppi (1990) upstairs markets benefit traders who wish to trade but do not want orders to be revealed in the downstairs market. After the announcement trades are more information-motivated and high volatility channels trades to the downstairs market.

Both binary dummy variables are significant $(p<0.01)$ throughout table 3 . This can be interpreted as meaning that the lengthening of the free trading period has increased both cross-broker trading in the downstairs market and in-house trading in the upstairs market. The importance of after-hours trading has decreased. As suggested by Fong et al. (2001) the upstairs market may serve some groups of traders better. These traders might demand extended trading hours (they are probably located in another time zone), lower execution costs and the ability to trade large orders with minimal price impact. ${ }^{13}$ The explanatory power based on the number of transactions seems to be somewhat weaker than FIM trading volume. This indicates that FIM volume and the number of transactions capture different dimensions of the trading activity. For example, the proportion of the number of transactions traded on a cross-broker basis in the downstairs market has increased with the intraday volatility after the announcement, DVOLA, but the same does not apply to the FIM volume.

The same additional tests are performed as in section 4.1. The analysis is also performed using only one stock class per firm (the most traded) in the sample. Despite the loss of observations the inferences hold for both samples.

13. Foreign ownership has enormously increased in Finnish HSE-listed companies during the research period. In 1993, restrictions on foreign ownership were abolished with a few exceptions, and during the following years foreign ownership grew rapidly. Foreign owners are generally large traders and they have concentrated their investments on large Finnish firms so they probably prefer to trade in the upstairs market. 


\section{Summary and Conclusions}

This paper, the issue of traders' choice of trading environment around an anticipated information event is addressed. In spite of active research on the use of trading venues little attention has been paid as to just how traders consider and use different trading venues around the informational events. Unique data from the Helsinki Stock Exchange provides a long time span with detailed information on investors' behavior in different trading venues. The data indicates whether the trade is executed in the upstairs market or in the downstairs market and whether the trade is internalized (i.e. same-broker trade) or externalized (i.e. cross-broker trade). The main objective of the study is to analyze whether an earnings announcement affects the use of the trading venues. Prior research suggested that trading around an earnings announcement is affected e.g. by pre-disclosure information asymmetry, the information content of the announcement, differential interpretations of the announcement, production of new private information and firm size. This paper suggests that interim earnings announcements affect where trades are executed.

The results indicate that an anticipated announcement stimulates downstairs trading before the announcement event. This suggests that an announcement increases traders' needs to trade anonymously given that upstairs brokers can effectively screen out information-motivated orders as suggested by Smith, Turnbull and White (2001). Thus, an anticipated announcement increases trading costs in upstairs markets relative to costs in downstairs markets. After the announcement trading costs in upstairs markets seem to be lowered.

Further analysis reveals that the relative use of the trading venue is related to liquidity and volatility around the interim earnings announcement. In line with Madhavan and Cheng's (1997) proposition, a positive relation is found between liquidity and the proportion of internalized upstairs trades. Also high volatility seems to be related to the proportion of internalizing. During the pre-announcement period high volatility in the downstairs markets benefits innocent liquidity traders by providing more room for price negotiation in the upstairs market. The announcement event affects this relation. After the announcement trades are more information-motivated and high volatility is associated with a larger proportion of downstairs trading. This is probably related to the traders' willingness to benefit from the announcement. This is consistent with Smith, Turnbull and White 
(2001), who suggest that information-oriented trades are executed in the downstairs market.

The present paper may be used to address a variety of important issues. For example, an uninformed liquidity trader can assess whether a forthcoming announcement affects the costs of transacting in the upstairs market. Moreover, it provides views to consider which factors are worthwhile to follow when deciding upon the trading venue around the anticipated announcement. Thus, the paper could be adopted to evaluate how investors select the trading venue around the anticipated information release. Keeping in mind the specific context of this paper, the results cannot necessarily be generalized to other markets since trading structures in different stock exchanges may affect the results. Also given a wide variety of listed companies with different size, liquidity, pre-disclosure information (e.g., differences in analysts' coverage) and earnings management activity, the traders' need to consider the trading venue choice around the announcement may differ across stocks. This calls for further international research focusing on trading in the presence of multiple markets. Nevertheless, from a more general perspective, the results of this study indicate that the announcement event may have implications also for the trading venue.

\section{References}

Acker, D.; Stakler, M.; and Tonks, I. 2002. Daily closing inside spreads and trading volumes around earnings announcements. Journal of Business Finance and Accounting 29: 1149-1179.

Bamber, L. S.; Barron, O. E.; and Stober, T. L. 1997. Trading volume and different aspects of disagreement coincident with earnings announcements. Accounting Review 72: 575-597.

Bamber, L. S.; Barron, O. E.; and Stober, T. L. 1999. Differential interpretations and trading volume. Journal of Financial and Quantitative Analysis 43: 369-386.

Barron, O. E.; Byard, D.; and Kim, O. 2002. Changes in analysts' information around earnings announcements. Accounting Review 77: 821-846.

Bessembinder, H., and Venkataraman, K. 2004. Does an electronic stock exchange need an upstairs market? Journal of Financial Economics 73: 3-36.

Booth, G.; Kallunki, J-P.; Lin, J-C.; and Martikainen, T. 2000. Internalization and stock price clustering: Finnish evidence. Journal of International Money and Finance 19: 737-751.

Booth, G.; Kallunki, J-P.; and Martikainen, T. 2001. Liquidity and the 
turn-of-the-month effect: evidence from Finland. Journal of International Financial Markets, Institutions and Money 11: 137-146.

Booth, G.; Lin, J-C.; Martikainen, T.; and Tse, J. 2002. Trading and pricing in upstairs and downstairs stock markets, Review of Financial Studies 15: 1111-1135.

Cheng, M., and Madhavan, A. 1997. In search of liquidity: An analysis of upstairs and downstairs trades. Review of Financial Studies 10: 175-204.

Fong, K.; Madhavan, A.; and Swan, P. L. 2001. Why do markets fragment? A panel-data analysis of off-market trading. Working paper. University of Sydney.

Garman, M., and Klass, M. 1980. On the estimation of security price volatilities from historical data. Journal of Business 53: 67-78.

Glosten, L.R. 1994. Is the electronic open limit order book inevitable? Journal of Finance 49: 1127-1161.

Godek, P. E. 1996. Why NASDAQ market makers avoid odd-eighth quotes. Journal of Financial Economics 41: 465-474.

Grossman, S. J. 1992. The information role of upstairs and downstairs trading. Journal of Business 65: 509-528.

Hedvall, K. 1996. To trade in- or outside the limit order book? An empirical study of the use of the automated trading system at the Helsinki Stock Exchange. Journal of International Financial Markets, Institutions and Money 6: 93-124.

Huang, R. D., and Stoll, H. R. 1996. Dealer versus auction markets: A paired comparison of execution costs on NASDAQ and the NYSE. Journal of Financial Economics 41: 313-357.

Kandel, E., and Pearson, M. 1995. Differential interpretation of information and trade in speculative markets. Journal of Political Economy 103: 831-872.

Keim, D. B., and Madhavan, A. 1996. The upstairs market for large-block transactions: Analysis and measurement of price effects. Review of Financial Studies 9: 1-36.

Kim, O., and Verrecchia, R. E. 1991. Trading volume and price reactions to public announcements. Journal of Accounting Research 29: 302-321.

Kim, O., and Verrecchia, R. E. 1994. Market liquidity and volume around earnings announcements. Journal of Accounting and Economics 17: 41-67.

Kim, O., and Verrecchia, R. E. 1997. Pre-announcement and event-period private information. Journal of Accounting and Economics 24: 395-419.

Lee, C. M. C.; Mucklow, B.; and Ready, M. J. 1993. Spreads, depths, and the impact of earnings information: an intraday analysis. Review of Financial Studies 6: 345-375.

Seppi, D. J. 1990. Equilibrium block trading and asymmetric information. Journal of Financial Economics 19: 73-94.

Smith, B. F.; Turnbull, D. A.; and White, R. W. 2001. Upstairs market for principal and agency trades: Analysis of adverse information and price effects. Journal of Finance 56: 1723-1746. 
White, H. 1980. A heteroskedasticity-consistent covariance matrix estimator and a direct test for heteroskedasticity. Econometrica 48: 817-838.

Vieru, M. 1998. Pre-disclosure information asymmetry and information content as a means of explaining trading volume responses to interim earnings announcements in a thinly traded stock market. Finnish Journal of Business Economics 47: 323-346.

Vieru, M. 2002. The impact of interim earnings announcements on the permanent price effects of trades on the Helsinki stock exchange. Journal of Multinational Financial Management 12: 41-59. 